\title{
THE SETTLEMENT EXPERIENCE OF SALVADORAN REFUGEES
}

\author{
by
}

Veronica Escobar Olivo, BA, Ryerson University 2018

\begin{abstract}
A Major Research Paper
presented to Ryerson University

in partial fulfillment of the requirements for the degree of Master of Arts in the program of Immigration and Settlement Studies
\end{abstract}

Toronto, Ontario, Canada, 2019

(c) Veronica Escobar Olivo, 2019 


\section{AUTHOR'S DECLARATION FOR ELECTRONIC SUBMISSION OF A MAJOR RESEARCH PAPER (MRP)}

I hereby declare that I am the sole author of this Major Research Paper. This is a true copy of the MRP, including any required final revisions.

I authorize Ryerson University to lend this MRP to other institutions or individuals for the purpose of scholarly research.

I further authorize Ryerson University to reproduce this MRP by photocopying or by other means, in total or in part, at the request of other institutions or individuals for the purpose of scholarly research.

I understand that my MRP may be made electronically available to the public. 


\title{
The Settlement Experience of Salvadoran Refugees \\ Veronica Escobar Olivo \\ Master of Arts 2019 \\ Immigration and Settlement Studies \\ Ryerson University
}

\begin{abstract}
This narrative qualitative study explored the lived experiences of Salvadoran refugees who came to Canada after fleeing the civil war in El Salvador. The research aimed to examine the experience of Salvadoran refugees who arrived between 1980 and 1992. During this period, the Canadian government enacted special measures which allowed for Salvadorans to seek refuge in Canada. The experiences shared by participants explored their experience with the traumas of war, migration and eventual settlement in Toronto. The theoretical framework drew on the coloniality of power and structuration theory. These experiences were considered within a broader context of what it meant to be a Salvadoran refugee in Toronto, both in ongoing connections to their country of origin and their country of settlement over thirty years later. The narratives of the participants provide insights into the complex negotiations into the experiences of refugees forced to flee and reorient themselves in a new society.
\end{abstract}

Key words: Salvadoran, refugees, experiences, civil war, identity, Latinx, Toronto 


\section{Acknowledgements}

I could not have completed this work without the unwavering support of those around me. First and foremost, I would like to thank my mother without whom none of this would have been possible. Her dedication to my studies has been what has motivated me to keep going.

I am indebted to my supervisor, Henry Parada, whose guidance and tough love propelled this research forward. Your dedication and passion for my topic kept me working as hard as I did. I would also like to thank Myer Siemiatycki for agreeing to be my second reader and for encouraging this topic when it was only a bud of an idea.

I would like to thank those individuals along the way who have encouraged me, both professionally and emotionally. To Dr. Alan Sears and Dr. Heather Rollwagen, I would like to thank you both immensely for providing me with nothing but encouragement and kindness. I would like to thank Luis Carrillos for all his help with this research and investment in this project.

To the rest of my family who have believed in me throughout this journey. My brother, my godmother, my grandmother, grandfather, uncle and aunts all of who I am grateful for. To my friends who have dealt with my endless crises and countless hours of theoretical jabber, I owe you.

Finally, to those who shared their stories with me and trusted and welcomed me with open arms. Without them this MRP would not exist. It was a pleasure to hear your stories and understand the history to which I am intrinsically bound. Their voices are invaluable to me. 


\section{Contents}

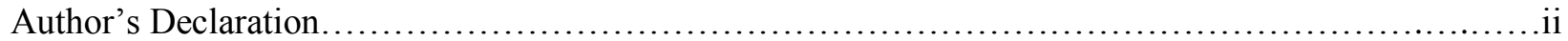

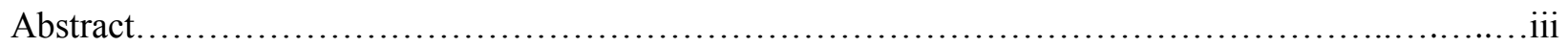

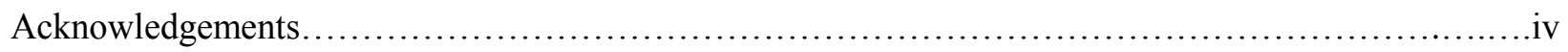

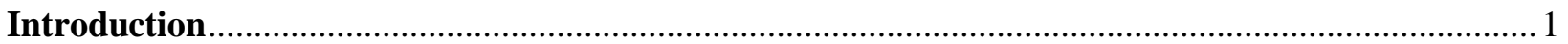

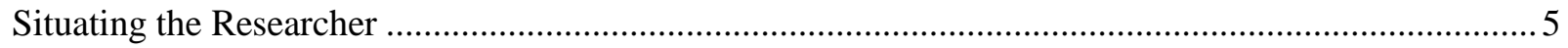

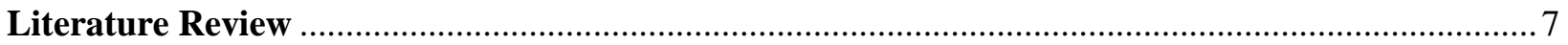

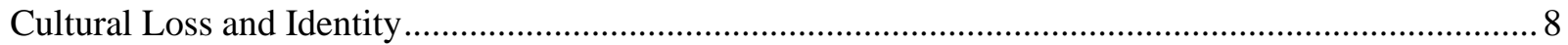

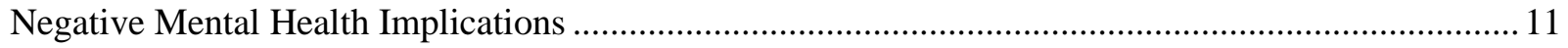

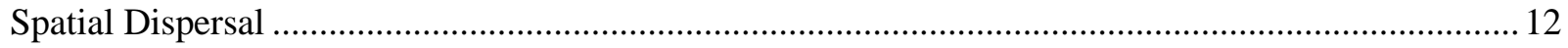

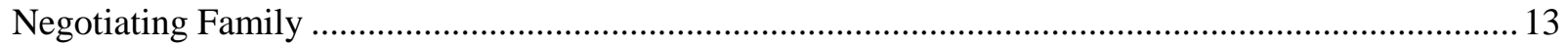

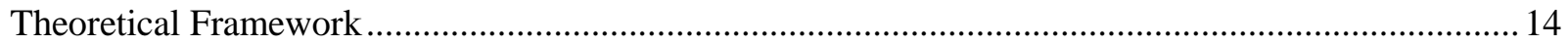

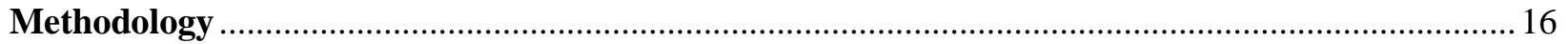

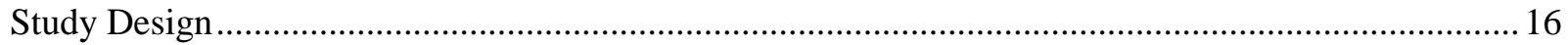

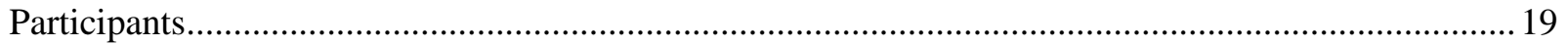

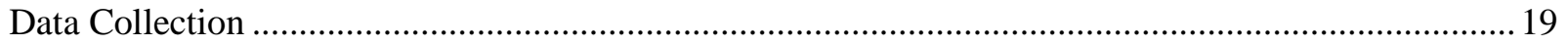

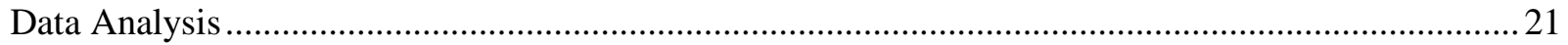

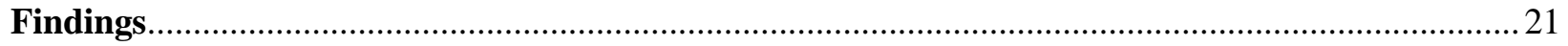

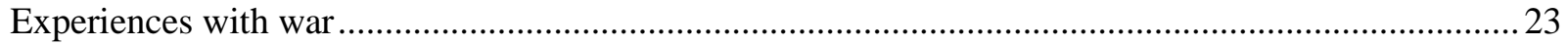

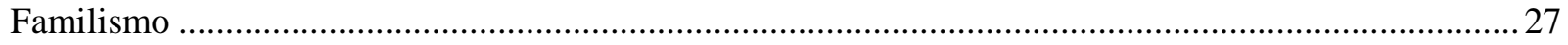

Forced to leave

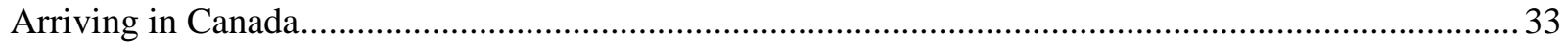

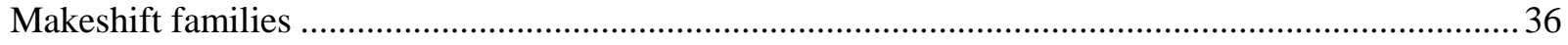

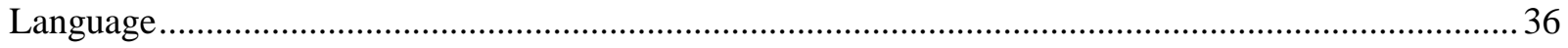

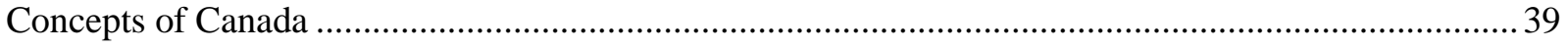

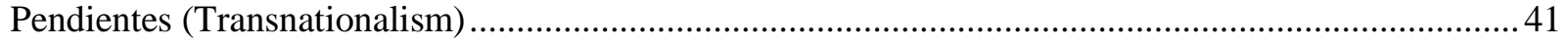

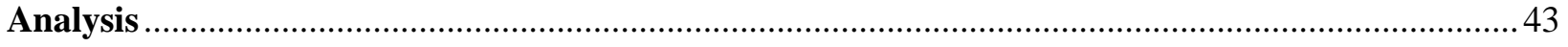

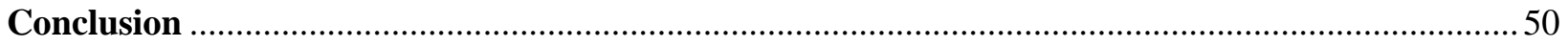

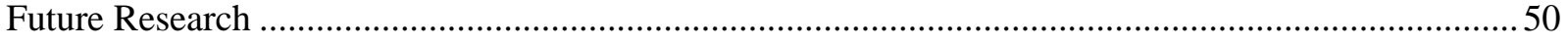

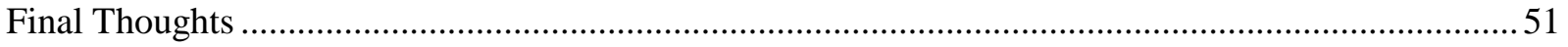

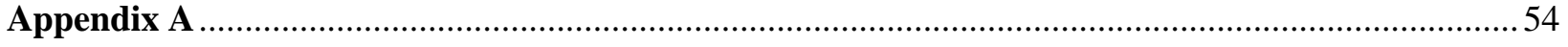

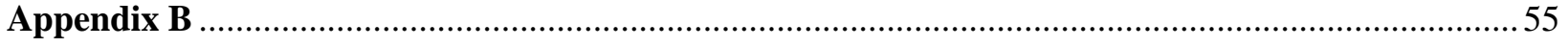

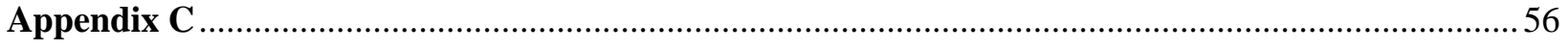




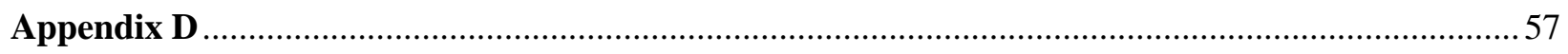

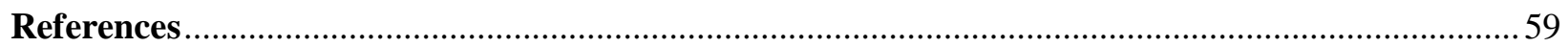




\section{Introduction}

It was never officially declared, but the civil war in El Salvador would last over a decade and would leave more than 75,000 people either murdered or disappeared (Dezza, 2017). The war formally ended in 1992 in Mexico City in the Chapultepec Castle sponsored by the United Nations, but its effects would change the country indefinitely.

The United Provinces of Central America gained independence from Spanish colonial rule in 1821. The Republic of El Salvador was established in 1839, following its dismantling (Da, 2002). From its inception, El Salvador experienced chronic political and economic turmoil, characterized predominantly by nondemocratic authoritarianism and unstable relations with neighbouring countries (Da, 2002; Ching, 2014). While officially, formal rules had been created to explain how elections and politics were to be conducted, the reality often diverged from constitutional rules that had been set in place (Ching, 2014). Frequent military coups marred intended democratic elections.

It was not until 1931 that the first real democratically elected president took office in El Salvador. The radicalization of the growing urban middle class began to mobilize during the 1920s; skilled workers, peasants and students reacted strongly to the United States' intervention (Gould and Lauria-Santiago, 2004). Thousands of Salvadorans, both from the middle and peasant classes vehemently opposed U.S. actions in neighbouring Nicaragua and protested by raising funds for Augusto Cesar Sadino and organizing rallies (Gould and Lauria-Santiago, 2004). Public discourse critiquing the unequal distribution of wealth continued to grow, and newspapers frequently published editorials critiquing the economic structures in the country 
(Gould and Lauria-Santiago, 2004). President Romero Bosque broke the authoritarian cycle, setting forth the Romero reforms which enabled a genuinely democratic election (Ching, 2014).

Reformist candidate Arturo Araujo became the first democratically elected president of El Salvador, although his presidency would last for only a short period of ten months (Ching, 2014). On December 2, 1931, the coup began with a machine-gun assault on the presidential palace. Araujo was able to escape, but realized that he would likely be unsuccessful; on December $4^{\text {th }}$, he turned over his presidency and fled to Guatemala (Ching, 2014).

In January of 1932, a peasant uprising rose in opposition of the government. Within three days, they had gained control over a dozen municipalities and temporarily appeared to have a chance at challenging the regime. The government quickly sent in reinforcements and would begin what has since been called la matanza (the massacre) (Ching, 2014). It is estimated that between fifteen to thirty thousand peasants were massacred and these deaths would fortify the complete military government control (Da, 2002; Darling, 2008).

The growing unrest of the Salvadoran Left before the 1932 massacre would function as the starting point for the re-mobilization in 1979. Between the coup which overthrew Araujo and the civil uprising, many presidential elections were held, but the patterns before the 1931 elections resurfaced and military candidate invariably won. By 1977, General Carlos Humberto Romero had won the presidency, representing the Party of National Conciliation (PCN), but the legitimacy of his election was openly challenged, and the party was accused of resorting to fraud (International Commission of Jurists [ICJ], 1979).

In addition to the internal dispute, neighbouring countries of Central America were also experiencing unrest, and the external battles were making Salvadoran officials uneasy when they 
considered the fate within their borders (Darling, 2008). Outrage against the political climate continued to mount, and the government retaliated with increasing violence. Romero's presidency was no longer considered adequate in quelling the surmounting civil unrest so that by October of 1979, a military coup overthrew his government (Amnesty International, 1980).

The coup succeeded in intensifying the dissatisfaction of insurgents who mobilized under a single organization The Frente Farabundo Marti Nacional. Their demands at the time included: direct democratic political participation, land and economic reform, government intervention in the economy and a restructuring of the military and police (Gonzalez-Perez, 2006). The military government would refuse to comply, and the ferocity of the attacks increased, both in efficiency and violence (Darling, 2008).

The viciousness of the surmounting war led to the increase of emigration from this region. Within five years of its commencement, 52,000 people have been killed, most of which had been civilians (Shayne, 1999). Bodies were left raped, tortured and mutilated on the streets, and the entire country was rendered an unsafe war zone (Shayne, 1999).

As the war continued, the government did nothing to aid the displaced, treating everyone as a threat. In May of 1980, hundreds of people were killed by government troops as they tried to cross the Sumpul River into Honduras in search of safety (Amnesty, 1981). Throughout the 1980s, one-quarter of the population were uprooted from their homes and civilians' lack of direct participation in the conflict did not warrant them any level of protection (Simmons, 1993). The war would amass an estimated 1.5 million refugees who fled from El Salvador to other parts of Central America, Mexico, the United States and Canada (De La Cruz, 2017). 
Before 1979, immigration to Canada from El Salvador has been nearly non-existent (Simmons, 1993). Following the war, the number of migrants increased, particularly those arriving as refugees. Between 1981 and 1985, approximately 3,000 refugee claimants arrived annually (Ryan, 1988; Simmons, 1993). In 1981, the Canadian government enacted a special measure which facilitated the admission of Salvadoran refugees, allowing for evaluation against a relaxed criterion (Ryan, 1988). By 1993, an estimated total of 37,000 Salvadorans had arrived, the highest group of Central Americans admitted to Canada as refugees (Da, 2002; Ryan, 1988; Simmons, 1993).

Following the Second World War, Canada worked strategically to erase the darker policies of its past; in 1951, it chaired the United Nations (UN) committee that drafted the 1951 UN Convention on Refugees which protected against refoulement (García, 2006). In the following years, Canada's policies became more empathetic towards refugees, accepting not only Convention refugees, but also members of designated classes; these classes were those who did not meet the strict definition of "refugee" as set out under the 1951 Convention but were considered to live in dangerous situations (Hathaway, 1988; García, 2006). Canada’s new dedication to an open policy generated its reputation as a compassionate nation; by the early 1990s, Canada stood second only to Sweden in ratio of resettled refugees to total population (García, 2006). The civil war in El Salvador coincided with Canada's newfound dedication to humanitarian crises and Canadians were particularly sympathetic towards Central American given that they too "must live in the shadow of the US superpower". By the mid-1980s, 30 to 40 percent of mail received by the Prime Minister at the time Brian Mulroney concerned the Central American crisis (García, 2006, p.145). 
Data from the 2011 census showed that among the Canadian foreign-born population who declared a Latin American origin, Salvadorans constituted the third-largest group (Armony, 2014). The numbers indicate the successive waves in which Latin American migration occurred to Canada, particularly regarding Salvadorans. Many post-migration variables can affect the settlement process of refugees, including their socioeconomic status (Jacob, 1994). The Salvadoran community in Canada has been characterized by low incomes, high poverty and high welfare dependency (Poteet and Simmons, 2016). In addition to arriving under difficult migratory circumstances, Salvadoran refugees arrived in Canada during a period when the economic opportunities for all immigrants were beginning to go into significant and steady decline (Poteet and Simmons, 2016).

\section{Situating the Researcher}

My first interaction with the political situation of El Salvador during the civil war was not like the one shared in the previous section. It did not include statistics or a linear timeline nor was I told the history which had set the events in motion. I was raised by parents who lived in El Salvador during the period of the war and one who migrated to Canada as a refugee. Despite their first-hand experiences, there existed a disassociation from the events, so that as I grew, I did not realize there was something to be talked about. When I finally did, the reality of its brutality took place only as I began my own research. In a twist of events, the statistics and numbers seemed more real to me than the living, breathing people in my life who had lived through the realities of war yet did not address them.

I did not hear the complete story of why my father left El Salvador until I began graduate school. In one of our courses, we were assigned the task of sharing with the class our immigration stories. They could be personal experiences or as far back as we had to go in order 
to trace them. I did not realize at the time how unacquainted I was with my father's story. Throughout my life, our relationship has been tumultuous, and it was not until I began the journey of this research that I began to understand how intrinsically connected his experience as a refugee has shaped him, our relationship and ultimately, me.

There exists an intrinsic link in the effect that family bonds have in the subsequent placemaking and identity negotiations which take place between parents and children. As Carranza (2015) found in her work with mothers and daughters, there is a balancing act which Salvadoran children must undertake in an attempt to make sense of their relationship with their traditional parents and the new country of reception.

Being the child of refugees, I am researching a topic which I have never had to personally confronted. That is not to say that the trauma of the narrative does not impact me. Carranza (2015) argues that refugees' experiences serve as the framework for their meaning-making process and subsequently impact the strategies they use to raise and support their children. Poteet and Simmons (2016) found that Central American youth were often hugely affected by the difficult circumstances under which their parents migrated.

My positioning as a second-generation Salvadoran daughter of refugees has been everchanging. As Parada (2012) argues, identity is a site of struggle and contention, a fluid reality rather than a static one. Understanding my positionality throughout this research is vital; while I am of a Salvadoran background, I was born in Toronto and spoke English as my first language. My experience as a racialized body is also distinct; I am of a lighter skin tone and have been described throughout my life as ethnically ambiguous. While generally I have been imposed the role of an ethnic other, I have rarely been labelled with Central American stereotypes. 
As Carranza (2018) notes, it is essential to position me in the context of the Global North-South relations when examining the coloniality of power. I was born and raised in Toronto, speak English as my first language, and have been educated in the Canadian education system my entire life. While I maintain a strong connection and interaction with my homeland, my entire pattern of knowing, understanding and acknowledging knowledge production has been entirely constructed in the Western world.

Even in writing this research, I am aware of the dichotomy of my positioning; while addressing the colonialism inherent in the racialized existence of Salvadorans living in Toronto, I continue to operate within its confines. My work diligently follows the standards set by Western academia in an attempt to legitimize the work I have done, thus producing research that is thorough and subsequently "valid." Quijano (2000) argues that rational knowledge has been constructed from a strictly Eurocentric perspective, one which does not consider the experience of the colonized. The internalization of these knowledge perspectives acts so that we adapt Eurocentric intersubjective traits, despite being profoundly different. This internalization, in turn, creates a distorting effect, so that we are never able to reflect correctly on the partial and distorted conceptualization of the self (Quijano, 2000).

\section{Literature Review}

The main issues explored in this literature review is the experience of the Salvadoran refugee settlement experiences in the Greater Toronto Area (GTA). There were four prominent themes in the literature reviewed: cultural loss and identity, negative mental health implications, spatial dispersal, and negotiating family dynamics. 
The Ryerson University Library Database was used to retrieve articles with the following search terms: Salvadorans in Canada, Salvadoran settlement in Toronto, Salvadoran refugees, Latin American settlement in Canada, second-generation Salvadorans, trauma and refugees, El Salvador and Canada. The literature review used the following keywords: Salvadoran, settlement, refugees, Latin American and Toronto.

The number of articles used was approximately forty articles, which focused on a variety of themes. There does not exist a significant amount of research specific to the Salvadoran community in the GTA. Thus, articles relating to the general Latinx ${ }^{1}$ experience in Toronto, the general experience of refugees in Canada and finally, the specific experience of Salvadoran refugees in the GTA were examined.

\section{Cultural Loss and Identity}

Given its relatively small size and recent emergence, the Salvadoran experience is often grouped in with the Latinx community (Parada, 2012). It is essential to recognize that Latinx experiences in Canada are neither static or complete; however, Latinx individuals in Canada do create new identities based on their collective experiences of marginalization (Veronis, 2007). Studies have found that some challenges do affect the Latinx community as a whole.

Part of the Latinx experience in the GTA is the required learning of a new language. Particular aspects of culture, such as language aid in fortifying bonds between interethnic individuals. Cervantes-Rodriguez and Lutz (2003) stipulate that Spanish language retention has served Latinx communities in the United States to fortify their minority identity, particularly when enduring racism and discrimination. Retaining language on a community basis can actively

\footnotetext{
${ }^{1}$ Latinx is a gender-neutral alternative to the term "Latino" or "Latina"
} 
aid migrants in their acculturation process. Language serves as the basis for a sense of belonging; the association between language and the territorialization of space (Cervantes-Rodriguez and Lutz, 2003).

Additionally, Latinx individuals become further isolated by accent discrimination. Latinx migrants are faced with discriminatory hiring practices based on accents or insistence of learning to speak English (Carranza, 2009; Poteet and Simmons, 2016). The idea that English is synonymous with progress and good citizenship is rooted in the cultural hegemony of the North (Cervantes-Rodriguez and Lutz, 2003). The power dynamics present in language can cause distrust in cases of mutual incomprehension and further isolates Latinx migrants unable to acquire what is considered proper language skills (Jacob, 2004).

Both Carranza (2018) and Parada (2012) discuss their experiences as Salvadoran migrants living in Canada when moving through spaces in both the Global North and South. For Carranza (2018) this has created a dichotomy of existence, one that sees her surrounded by mistrust in the global south due to the perception of her role as a Western agent and, as Parada (2012) describes, mistrust in Toronto so that in neither geographic location are CanadianSalvadorans living accepted. As a result, individuals form hybrid identities and undergo identity negotiations in order to reconstruct themselves to navigate these dynamic forms of oppressions within all types of institutions (Parada, 2012). Likewise, Sky (2016) examines her positioning as a racialized body within a colonized framework, comprehending how she internalized the colonial North. In examining this, all studies begin to understand and grapple with the idea that the division of the oppressor and the oppressed is not static, but instead is more insidiously interwoven in identity formation (Carranza, 2018; Sky, 2016). 
For refugees, the cultural loss is further exacerbated by the circumstances under which they fled their countries of origins. A refugee's intrasubjective experience is negatively impacted as they seek to redefine even the most fundamental aspects of their lives. Jones (1994) found that refugees went through a phase of introspection, which resulted from a state of mourning for their country. Refugees tended to reject their surroundings as they attempted to retain the everchanging pieces of their lives.

Carranza (2009) notes that the settlement experience of people of colour contradicts the Canadian policies of multiculturalism which do not necessarily reflect the lived reality of Salvadoran refugees. In his research, Parada (2012) notes the role of ethnicity in the negotiations of otherness ascribed to him by those in Canada. There is sufficient evidence to suggest that migrants from El Salvador are discriminated against based on their physical features, skin tones and language capabilities which all factor heavily into both perception of and ability to adapt to their new environment (Jacob, 1994; Young, 2001; Holt and Laitsch, 2016; Carranza, 2009).

Despite the lack of a significant cultural or geographical Salvadorean community in the GTA, political organizing was substantial. The politicized context of departure of Salvadorans influenced the activities of the refugees who settled in the GTA. Ginieniewicz (2007) found that the political engagement of migrants was affected if they arrived from political countries at the time of migration. In the case of Salvadorans, the political situation which refugees fled resulted in the development of transnational political organizations in Canada that aligned with different parties and organizations which existed in El Salvador (Bernhard, Goldring and Landolt, 2011). 


\section{Negative Mental Health Implications}

The mental health of Latinx immigrants is strained by the lack of network supports, which are commonly found within their culture. One of the defining features of the family in Latin American is the strong family orientation, which often includes both the nuclear and extended family members (Anison and Merali, 2018; Carranza, 2012). These structures are disrupted at the time of migration. New arrivals depend on their cultural communities to help reduce the stress of cultural changes, and many researchers have emphasized the importance of a social support network for all newcomers (Jacob, 1994). The lack of networks can create undue stress on individuals accustomed to larger support systems. Ansion and Merali (2018) found that Latinx parents often reported adverse mental health outcomes as a consequence of the loss of the extended family network.

Anison and Merali (2018) found that Latinx immigrants are often faced with challenges of depression due to cultural loss and feelings of uncertainty regarding how to cope in a new environment. The various levels of negative mental health impacts often lead to different levels of ability to adapt, as migrants attempt to negotiate the cultures they bring with them in the context of the new one.

When examining the specific experience of refugees, Carranza (2008) and Riaño-Alcala (2008) indicate that the historical memories of individuals significantly impact their settlement experiences. The personal past experiences of trauma and loss alter how individuals make sense of the past, present and future. Ethnographic studies on refugees over time illustrate the long duration of the impacts made by uprooting and displacement, which suggest that resettlement is an ongoing process for many refugees (Riaño-Alcalá, 2008). 
There also exists the transformation of the refugee's sensory experience and awareness of danger, so that individuals might live with a fear they did not carry in their country of origin (Riaño-Alcalá, 2008; Carranza, 2012). The experience of violence and difficult migration negatively impact the subsequent settlement of refugees and their overall well-being (Poteet and Simmons, 2016).

Jones (1994) identified that the reason for departure significantly affected the stress levels of Salvadoran migrants and their ability to adapt. Given the political climate under which refugees from El Salvador emigrated from the country, Carranza (2012) found that fear and trauma had an undeniable impact on the acculturation process and significantly impacted Salvadoran women's mental health. Additionally, in cases where migrants have arrived and were pending refugee approval, the impending immigration hearings often further exacerbated the pain and uncertainty that accompanied fleeing the political upheaval of El Salvador (Carranza, 2012).

\section{Spatial Dispersal}

Loss of extended family is a common theme among newcomers. Historically, other ethnic groups which have migrated to the GTA have been able to create systems of social support outside their biological families, by basing their social networks on shared ethnic identity and geographic clustering. The 1970s saw the mass migration of Portuguese to Toronto and this group was able to garner a level of unity, mutual aid, support and regular interactions among other Portuguese individuals by settling in particular areas of the city to remain close to others of the same cultures (Nunes, 1986). Spatially segregated communities based on ethnic identities might be considered a site of repression, but the act of place-making can aid in constructing a safe space for racialized individuals to live, move and interact with those of similar ethnic 
background and together successfully negotiate their spatial rights and rights to citizenship (hooks, 1990; Teelucksingh, 2006; Veronis, 2007).

The geographical unity which aided groups such as the Portuguese does not exist for the Latinx community in the GTA. There is not a significant concentration of Latinxs in the GTA and are instead dispersed throughout the city (Veronis, 2007). Multiple factors contribute to the spatial dispersion of the Latinx community. These include internal divisions along national, racial, and class lines, which complicate the organization of a single unified community (Veronis, 2007).

\section{Negotiating Family}

Cultural loss, adverse mental health impacts and spatial segregation all contribute to the different acculturation rates Latinx immigrants and their children can achieve. While children are likely to embrace the new cultural expectations and norms of Canada, the incoming immigrants are more likely to struggle as they navigate the new country (Carranza, 2015; Anison and Merali, 2015). Immigrant parents must simultaneously navigate their acculturation and the acculturation of their children, which includes identity formation and need to belong (Carranza, 2015).

Different rates of acculturation destabilize the typical bonds which hold families together as immigrant children attempt to navigate the cultural expectations present both in the home and in their day-to-day lives outside of it (Carranza, 2015). Despite the accelerated rate of acculturation for immigrant children, Poteet and Simmons (2016) found that none of the youth they interviewed felt that they had integrated entirely into Canadian culture and society.

Carranza (2012) argues that acculturation is a family process, by which whole families negotiate new roles and identities in the family unit in their new country of settlement. A recent 
study examining the relationships between Salvadoran mothers and their daughters found that both sides must renegotiate their power and control within the relationship in a very new and distinctive culture. This ongoing negotiation comes as a result of attempting to navigate the new culture while dealing with the pre-existing cultures and traumas with which refugees, in particular, arrive in Toronto (Carranza, 2015).

\section{Theoretical Framework}

The theoretical frameworks used in this study are structuration (Giddens, 1984) and the coloniality of power (Carranza, 2018; Quijano, 2000).

In understanding the structures which impact the reality of racialized bodies from El Salvador, the theory of coloniality of power was used in this study. Coloniality focuses on the pattern of power, which emerged as a result of colonialism (Misoczky, 2011). This theory recognizes the various ways in which societal structures set out to produce knowledge based on ideas of race and cultures, using institutions which dominate society to reinforce theses ideals (Misoczky, 2011). Part of examining coloniality includes seeking to understand which methods of knowing have been silenced, acknowledging the repressed subjectivities and the delegitimization of specific languages and knowledge (Quijano, 2000).

The establishment of a "universal" knowing has, in turn, created a standard based on Eurocentric hegemonic patterns of knowledge (Misoczky, 2011). Quijano (2000) argues that, as a result, racialized bodies are always considering standards of knowing and being which do not take into account the multiplicities of the colonized experiences. As such, colonized bodies attempt to examine themselves through a lens which does not and cannot depict them accurately. 
The rhetoric of modernity is often used to devalue and delegitimize the knowledge production of colonized bodies (Misoczky, 2011). Modernity is an exclusively Eurocentric concept, one which has historically legitimized and justified genocidal violence and Northern interference (Mignolo, 2007). This concept traverses' borders but is also reproduced within borders. Colonized bodies are perceived and understood as coming from regions which are less "modern" thus lack in progress that is inherent in Western nations. Colonized bodies that have moved into Western spaces are assumed to inherently lack knowledge and appropriate attitudes and behaviours based on this rhetoric of modernity (Mignolo, 2007).

Colonialism has left categorizations which are still used to navigate human relationships, identities and sense of belonging, as well as perceptions of whether individuals ought to belong (Carranza, 2018). As such, it is vital to recognize the role racialization and language plays in the identity formation and settlement experience of Salvadoran refugees.

Structuration theory was developed by Anthony Giddens (1984) to define an approach to social theory which recognizes both the impact of institutional and social structures, while simultaneously acknowledging the agency which exists to each individual operating in society.

The critical tenet in Giddens' (1984) argument is the duality of structure: structure and agent. Structure refers to the rules and resources ascribed in society that enable the regulation of specific behaviours to permeate time and space. These systems are reproduced by individual agents and collective groups, organized as daily practices. Structure then becomes both the mode of operation and the outcome: agents internalize behaviours normalized in society, thus delivering and reproducing the existing structures (Giddens, 1984). 
This proposes that social phenomena are not the product of either structure or agency, but rather than human agents draw on social structures in their actions (Jones and Karsten, 2008). Structure does not exist externally to individuals but instead is ratified in their day-to-day actions. This positions the human agent as non-ignoration, as structuration theory recognizes that there exists an element of agency in reproducing existing structures (Giddens, 1984). In this structure is both constraining and enabling the individual to choose in reproducing the social structure.

In his theory, Giddens (1984) established that neither solely micro- or macro-approaches to understanding society are sufficient on their own; instead, both approaches must be used in order to examine the recreation of existing social structure. Microsociology focuses on the activities of the individual, while macrosociology studies the most significant issues on a broader scope, understanding these issues as constraints which are impossible to escape on the individual level (Giddens, 1984).

In the context of refugees, this theory allows for the space in which structural and institutional practices influence the actions and choices made by individuals but also counteracts the homogenizing nature of the refugee label in their ability to make choices (Nourpanah, 2016; Carranza, 2008).

\section{Methodology}

\section{Study Design}

This study is a narrative qualitative design, used to study the lived experiences of Salvadoran refugees. Narrative and identity are often regarded as intimately connected (De Fina, 2015). Narratives are not meant to provide an objective truth; instead, narrative research intends 
to obtain a story that reflects the impact cultural factors have on the participant's interpretation of their position (Elliot, 2005). Singer (1995) argues that as individuals accumulate life experiences, their narratives are formed. These narratives provide an internal perception of reality, including their positioning in it. Narratives as individualized accounts of experiences and understand that stories are a way of constructing personal identity and negotiating agency (Andrews, Squire and Tamboukou, 2013).

For this study, an individually-oriented approach was used. As discussed previously, structuration theory was one of the theoretical frameworks of this theory. This theory recognizes the agency that individuals have in which individuals are capable of taking action to make a difference (Giddens, 1984). For theorists like Butler (1993), individually-oriented narrative work operates as more than a story, but also as a vehicle for agency. Through the articulation of their own story, interviewees can assert power by interpreting the world according to their realities and asserting this as truth (Andrews, Squire and Tamboukou, 2013). Narrative research enables those being interviewed to be perceived as more than just vessel of information; instead, it gives interviewees a centrality in the research in a way more structured interviews might not (Elliot, 2005).

In using coloniality of power as a theoretical framework, there is an ongoing attempt to situate the self within a colonized structure. Whether directly or indirectly, narratives contain an evaluation orientation (Andres, Aquire and Tamboukou, 2013). Parada (2012) identifies his selfnegotiation; as a racialized Salvadoran man, he has had to undertake the development of an everchanging narrative as he situates his "self" in his new context and renegotiates aspects of his identity. Narrative research replaces the questions of if or whether individuals have changed but instead asks how people navigate the everchanging reality constructively in a coherent way 
(Bamberg, 2012). This ongoing negotiation of the self is inherent in colonized bodies, impacting the narratives as participants attempt to reflect using Eurocentric intersubjective traits (Quijano, 2000).

The relationship between interviewer and interviewee influence the types of data that are collected (Dwyer and emerald, 2016). Mishler (1986) argues that obtaining narrative interviews serves in empowering interviewees by shifting the balance in power and engaging them as experts. The role of the researcher then becomes about a relational interaction with participants, treating participants as co-investigators since they are the ones providing the knowledge (Dwyer and emerald, 2016).

The research question for this study was: How do Salvadoran refugees who came to Canada between 1980 and 1992 describe their settlement process? The three objectives of this research were to explore the stories of Salvadoran refugees about their experience settling in the GTA, to understand how their migration impacted their understanding of themselves as racialized bodies in the Global North, and to understand the impact this understanding had on their family dynamics.

This research used purposeful sampling and snowball sampling. Purposeful sampling is a method which applies specifically to qualitative research (Charles, Gentles, Ploeg and McKibbon, 2015). This method requires access to key informants to whom the issues are of central importance (Suri, 2011; Charles et al., 2015). This method of sampling is not meant to exhaust all potentially relevant avenues, but rather to examine the complexity of specific conceptualizations (Benoot, Hannes and Bilsen, 2016). Identifying a target population ensures that experiences, perspectives and actions address the study's primary focus and concerns of the intended population (Bungay, Oliffe and Atchison, 2015). 


\section{Participants}

The recruitment process involved the creation of various types of recruitment material. This included a recruitment poster (See Appendix A), which was posted in community organizations associated with the Latinx community in Toronto. This included organizations such as the Hispanic Development Council and faith-based centres oriented to the Latinx diaspora which were emailed to help initiate recruitment with community members (See Appendix B). A digital version of the recruitment poster was also shared on the researcher's Facebook page. Potential participants were asked to contact the researcher directly via private messaging or email, rather than commenting on the Facebook post itself.

Potential participants were contacted by the researcher via email or phone using a recruitment script (See Appendix C). Selection criteria included Salvadoran individuals who arrived as refugees to Canada between the years of 1980 and 1992 and initially settled in the GTA. The time frame was selected based on the period in which the civil war in El Salvador and subsequent mass migration began and the year in which the Chapultepec Peace Accord was signed (McReynolds, 2002). Individuals would have had to initiate the migration process themselves, rather than having arrived as a sponsored individual or as a child with their parents.

\section{Data Collection}

This work draws on four semi-structured interviews with Salvadoran men and women who arrived in Toronto as refugees between the years of 1980 and 1992. Semi-structured interviews provide a method for engaging in an in-depth conversation about an individual's life and intimate experiences (Elliot, 2005). Through semi-structured interviews, the researcher can uncover the underpinning of a person's life and treats the individuals as an expert on the topic (Elliot, 2005). 
Each interview was based on the same interview guide, and the interviews ranged from one hour to an hour and a half. Semi-structured interviews provide the ideal method for discovering more about individuals' experiences (Elliot, 2005). Providing topic guidelines yet still allowing participants space to share their narratives as they deem relevant, allowing the flow of the conversation to be negotiated between the interviewer and the interviewed (Ellito, 2005). The interview guide (See Appendix D) was constructed to address the linear timeline of migration, initial arrival and current settlement experience.

Interviews were conducted in Spanish, English or both, depending on the participant's preference and comfortability. All interviews were audio-recorded. Given the objective of qualitative interviews to produce a more natural conversation between the interviewer and the interviewee, audio-recording has generally been considered the most effective way of achieving this. This allowed the interviewer to dedicate his or her full attention to the participant (Elliot, 2005). Audio-recording is also considered beneficial in capturing certain aspects of the interview that may have been lost should the researcher rely on their memory; pauses, intonations and laughter affect how the researcher interprets the meaning and their subsequent analysis of data (Elliot, 2005). Before commencing the interview, consent was obtained to audio-record and use the interviews for dissemination.

All interviews were transcribed directly from the audio file by the researcher and were permanently deleted immediately following transcription. Before transcription, audio files were stored on a password protected and encrypted Ryerson Google Drive to prevent anyone from obtaining the audio file before transcriptions could be completed. Completed transcriptions were scrubbed of all identifying information and stored on the same Drive. Only the researcher and her supervisor had access to full transcripts. 
The risk presented to participants was minimal, and the researcher took multiple steps to respect the privacy of participants. The participants were assured that their identities would be known only to the researcher and her supervisor. Each participant name was replaced with a pseudonym and any identifying information shared regarding specific places, names or people were removed from the data at the time of transcription. All interviews were conducted in a space where the participant could feel comfortable.

\section{Data Analysis}

A hermeneutic approach was used in this study, as it focuses on achieving a deeper understanding of materials through a detailed interpretation (Owolabi, 2001). Research in the hermeneutic tradition does not have a set of evaluative measures when examining narrative materials (Elliot, 2005). Instead, this method emphasizes the importance of empathizing with the participants of the research and developing an understanding of how they make sense of their reality (Elliot, 2005). This analysis focuses on how strategies are used by narrators to construct, negotiate and affirm specific identities they have ascribed to themselves (De Rina, 2015). In order to examine the narratives from this approach, the transcripts were all read over once to identify standout themes in an initial reading, before re-reading until standout similarities could be identified from the personal narratives of the stories.

\section{Findings}

The following section will discuss the participants' experiences of leaving El Salvador and settling in Canada. There were eight main themes which include: experiences of war, familismo, forced to leave, arriving in Canada, makeshift families, language, concepts of Canada and transnationalism. 
The participants included Rosa, who migrated directly to Canada from El Salvador after her husband applied for refugee status for both her and her daughter at the time. Rosa did not identify direct participation in the war in any capacity.

Isaac was a university student during the time of the unrest. He identified as being a political activist who was part of the communist party, thus targeted by the military government. He fled El Salvador with a friend after a few of his other friends were assassinated. Isaac left behind his wife and child, fleeing alone through Mexico and then the United States. He applied for refugee status at the Canadian consulate in the US where he was granted status. When he arrived in Canada, he would send for his family.

Elara self-identified as a campesina ${ }^{2}$ and worked in a daycare as part of a Jesuit organization which had been opened twelve years prior to the commencement of the war. Due to the religious support of activists and campesinos, the workers were considered enemies by the military. After the organization she worked at was raided and the employee files stolen by the soldiers, Elara lived in fear that she and her family would be killed for being associated with the Jesuits. She and her husband sought help from the Jesuit workers who aided them in applying for refuge in Canada, along with their two young children. They travelled through the United States to get to Canada.

Roberto identified himself as a campesino. He became involved with the Catholic Church as a catechist at the age of twenty-one, ten years before the start of the war. His religious work would eventually drive him out of his small town to San Salvador. He would be kidnapped by the military and left for dead but managed to escape and fled to Costa Rica. He lived there for a

\footnotetext{
${ }^{2}$ In Spanish-speaking regions used to refer to peasant farmer
} 
period before the Costa Rican authorities began to threaten him there too. Eventually, under the advice of a friend, he would apply for refuge in Canada for himself, his wife and four children.

\section{Experiences with war}

During the descriptions of why the participants had to flee El Salvador, all participants brought up poignant experiences of trauma during the war. Overall, participants did not identify these experiences as traumatic, nor did they seem uncomfortable in discussing the events of the war in a general way.

Of all the participants, Rosa was the only one who fled for general fear of violence at the time. She was not considered a threat by the military and left for reasons of a brighter and safer future for her child, rather than political persecution. Rosa's experience was not immune to navigating the dangerous circumstances of war and the inevitable traumas that came with it. Rosa described her daily commute to work:

It was hard because sometimes, you would travel to and from work and you'd see bodies lying around. People that have been assassinated before, they were left on the side of the road, and I saw bodies.

Rosa also recounted the general atmosphere of mistrust and animosity:

It was a hard experience to live with a war going on because you were afraid that if you went out, for example, I went to the market, if a person didn't like you, they could say you were a fighter and take you away and disappear you. There were no warranties or guarantees for people. We were just disposable items.

The language of the war remained with Rosa as she explained that anyone could "disappear you." Additionally, the imagery which she enacted of people as disposable items called back to the numerous bodies she had seen during her travels to and from work and the numbness with which they were disposed. For Rosa, those bodies became a symbol of the pointlessness of the 
war so that neither side was correct. Unlike other participants, she did not identify the

Salvadoran military as the absolute enemy. Instead she shared:

You were scared of the guerilla people and you were scared of the army, because the army did bad things too and they were suspicious of regular people, they saw a guerilla person in every person.

Rosa felt the need to explain why the army would be considered harmful in this scenario. While the other participants identified the inherent structural problems with the military, Rosa seemed to consider that generally, the military represented the protecting side. In the circumstance of war, she had to explain the military acted contrary to their presumed mode of acceptable behaviour.

Elara, who worked for a Jesuit organization at the time, was considered politicized by the military. Elara did not consider her position as a rebellion in any form. She worked in a daycare as part of a religious organization run by Jesuits that had opened twelve years before the war. The politicization of religion became obvious to the military government, but for Elara the connection still did not make complete sense. Instead, she interpreted her persecution as a byproduct of the general climate of violence:

For the war, because they started to bomb everything. The church, the clinic and everything. The daycare. They came to bomb us and the military took up where we were...then they said they were going to kill everyone who worked there.

Elara herself did not identify having decided to be involved or seem to consider her work as purposeful in any way. Instead, in recounting her story Elara described major players she considered to be at the risk of danger and gave the sense that the danger she was in occurred by association rather than fear of her as an individual: 
The parish, we- almost all the workers would sleep with the father [priest] because they would threaten him so we would go to his room to sleep there to protect him. Because if something happened there it would be like the Mozote massacre, there was going to be something like that. So, we slept there because if they killed him they'd have to kill all of us. And it was going to be big, so that's why we took care of him.

The insidiousness of the dangerous realities with which participants lived seemed to render the real dangers and discussions of their potential deaths. There was no one way that participants responded to the discussion of the traumatic events. Participants' recollection of these events varied from individual to individual. When asked about what it was like during the period of the civil war, Roberto and Rosa recalled their personal experiences, drawing on specific stories to illustrate their realities at the time. Roberto described a moment where his life was at risk. After refusing to participate in a march in support of the government, the army came looking for him at work. Roberto described how he had come to terms with the situation:

Well, I jumped onto the bus and escaped, but at three days they came for me at the restaurant, the same dressed in plain clothes, like eight men dressed in plain clothes. They made everyone get face down, including the manager and they took me, threw me in a car... They stopped the car; I was ready - one of the experiences of all this is that if one isn't prepared ahead of time, when the time comes one isn't ready to thank God, to remember their children. I was ready to die. I had given up.

Elara talked about the experiences she witnessed firsthand, though related dangers more to the organization and excluded her thoughts and feelings about what was happening at the time.

We saw that they killed the six Jesuits and then our priest since he was from Spain, they were looking for him to kill him, the Spanish embassy took him in to protect him. When we saw the priest wasn't with us anymore, we left, to seek refuge in a school of nuns. There they would arrive to plunder every night. 
Isaac, who was the only political activist and shared that he had been a member of the communist party, related the experience of the civil war more to the general structure of society. Describing the violence and death toll, Isaac adopted a language of collectivity:

The whole central America we spent- risked twelve years of war, many people died in that process, and the official figures say 75,000, but there were a lot more, right? More than 100,000 . Unofficially we were so many. So much sacrifice for the change- I don't see the change.

Isaac's language remained political. He adopted common words of 'we', as in 'we' risked twelve years of war. Even upon recounting numbers of those who died, Isaac identified with those who were killed 'we were so many.' Isaac grouped himself in with those who have died, continually identifying himself with the movement and the efforts of the movement.

Additionally, Isaac shared his frustration with the outcome of the war in general. He discussed sacrifices for the betterment of El Salvador, a sacrifice which he felt did not manifest in any significant transformation.

While overall participants remained relatively calm in their retelling, there were other moments when three participants became emotional during the discussion. Despite their ability to recall most events of the past without any visible discomfort, other recollections proved harder, indicating their continued attempt to navigate these memories.

For Elara, this included recalling how difficult it became when she and her husband attempted to leave El Salvador. The government of El Salvador detained her husband as they tried to leave and mistreated him in some form. When asked why they did this, Elara shared:

Because they said he was a guerrillero. And that they [the guerrilleros] shouldn't leave. They would say "guerrillero son of a bitch" things like that. Things like that, very hard. So yeah. But these things have passed. 
At that point, Elara had begun to cry, and the interview was paused until she felt comfortable enough to continue. Throughout the interview Elara had remained relatively detached when discussing the possibility of her death and even her husband's. It was the reality of his mistreatment and abuse, which triggered an emotional response from her.

Similarly, Roberto showed signs of continuing to live with trauma when discussing the death of his mother. Though he was able to recount his kidnapping and escape with relative ease, it was the passing of his mother, which triggered a strong reaction from him. Roberto shared:

The people that we loved were no longer there. My mother died in a bombing that took place. And that...that's hard.

Roberto teared up as well and took a few moments to compose himself. The loss of his mother impacted him in the way other events did not. This likely had to do with the unexpected manner in which she died. Even during a period of instability, Roberto formed a bracket of expectation. He anticipated that his life would be in danger because of the nature of his religious and civic affiliations. His mother, on the other hand, had had no involvement in the unrest and so her death was unexpectedly triggering for him.

\section{Familismo}

Common amongst all interviews was the recognition of the significance of the family in the Latinx community. The strong ties with families significantly impacted the level of expectation participants had in being able to navigate their daily lives and the level of help and responsibility they relied on from their loved ones. 
Rosa explained that when she lived in El Salvador, she was able to handle working, school and being a mother because of the support of her family.

I was taking chemistry and pharmacology, and I was working part-time as a sales clerk, and I was a mother... Economically it was hard. However, I had the privilege of having family around, so family used to help with taking care of my kid and I had the support of family whenever I needed, you know moral support, even economic support, I could count on family. My father, my mom, my mother-in-law, other close family and friends.

Counting on extended family members to weather daily tasks was a common experience for Elara and Rosa, and both noted the contrast when this support was no longer available. As in the quote shared by Rosa above, she noted the help of her family was a "privilege" one which was no longer accorded to her upon arriving in Canada. Similarly, Elara shared that navigating her own life and being able to attain her educational goals was made more difficult by the lack of family support in ensuring the safety of her children:

If I had had someone who would take care of my kids. My kids- that I hadn't been afraid to leave them...If the kids are young to have somewhere safe for them, like sending them to a daycare. That's what I think.

While not directly stating that having family in Canada would have proved beneficial, Elara did earlier on express her ability to make individual career choices in El Salvador because she could count on her family to provide a certain amount of help. Before leaving the country, she and her husband had become superintendents of a school and their tasks involved opening and closing the school. Later, her husband would get a job and she would return to school to become a seamstress. Elara briefly mentioned how her family supported them: 
We started to take care of a school like the superintendents. I would stay since I closed the hallway in the morning and closed them at night, and my husband would go to work. But then in the afternoon, I found someone from my family to do that for me, and I started at an academy for sewing.

Despite the deep connection and reliance on extended family, it was their dedication to their children, which became a significant motivator for Rosa, Roberto and Elara. For Roberto, the reality of how his actions impacted his family came when the police began to investigate him and found his daughter instead. While nothing happened to her, this moment proved significant for him in noting that it was time to leave:

So, the police were starting to investigate me. Two times they'd come to my house, and I had a daughter of about...12, I think she was. They came to my house and asked her about me. Things like that. There were more things all around where they wanted to intimidate me.

Rosa described her thought process in what finally motivated her to leave. While she shared no inclination to leave for her safety, it was the thought of a better life for her daughter, which finally propelled her towards seeking refuge elsewhere:

It got bad, too, right, so I wanted a safer future for my child. My child was four at the time, and I use to tell [husband] that El Salvador seemed really hopeless, that I was scared for the life of my child, [name]. I didn't see a secure future.

Elara, who knew that the military was likely to still come after her and her family, made a similar decision. She worried that both she and her husband might be killed because soldiers had stolen personnel files from the organizations when they sacked all the buildings owned. She and her husband sought help from Jesuit missionaries which had arrived in El Salvador and led the project that she had worked with for so long: 
We told them we didn't want to leave the kids orphaned if they even managed to stay alive. That's how we came so fast.

The family also rendered leaving incredibly tricky for participants. For Isaac and Rosa, the decision to leave was made more difficult by the consideration of having to leave family behind.

While Rosa waited to hear back about her pending refugee claim with the Canadian government, the impact of leaving her family dawned on her. Even with the threat of danger always looming, her connection with her family was a strong enough bond to make her reconsider her decision to flee to safety. It was the stronger bond with her daughter, which finally convinced her that she had to leave her father behind to provide a better future for her child.

To tell you the truth, I didn't want to come. I didn't want to come. I said, "I hope the thing doesn't materialize because I don't want to leave my father." But then you think about your child, the poor child is living in these uncertain times, and you think about her, and she might have a better future and safer place to come to. So, it was tough. To wait and to have to make that decision to come. It was tough.

Isaac shared a similar experience when deciding to leave both his nuclear family and extended family in search of a safer future. At the time, Isaac recognized the uprooting effect leaving in search of a better outcome would have, both on himself and his family.

It is hard. Because my eldest daughter was four - when I left, she was three...one decision involved a big impact. For example, leaving my mom. I always lived with my mom, my brother and taking that decision meant to stop seeing my mother.

For Elara, this sentiment was echoed. When asked what the hardest part was of leaving El Salvador, she shared that despite losing their home and all their belongings, leaving family was the most difficult: 
Leaving the family. Because they're still over there. And it's hard to bring them over. I think that was the hardest part. I think material things don't matter much.

\section{Forced to leave}

As shared above, leaving family behind had a significant impact on participants' reluctance to leave El Salvador. All participants shared some level of unwillingness to leave El Salvador, despite the dangerous events which were taking place during the time.

Isaac acknowledged that he had no desire to leave:

If there was no war, I would still be there. Before I never wanted to leave...I like El Salvador, I wanted to stay, but I am here. I don't know why things happen, we never plan, I never plan to leave, and I am here.

The magnitude of the war was not lost on Isaac as he recalled the dangers. After his university friends were assassinated for being involved in the communist party, Isaac knew that it was no longer safe for him in El Salvador and so he fled to the United States with another friend, leaving his wife and child behind:

But I took that decision because it was so dangerous, and I was already married with my wife, and I had my eldest daughter over there, and it was something that I had to ponder. There was a friend also that wanted to flee El Salvador, and we both made the plan to go in somewhere one day, and so we did, and the things in El Salvador was that every- I had a few friends that were assassinated and since we were involved in that political movement, so I had to leave, and that's why we came.

Despite her unwillingness, Elara knew that the dangers of the social climate and her presumed involvement in the guerilla was not going to disappear. The fear and uncertainty of whether she and her family would live drove her to make an incredibly difficult decision: 
The priest, the archbishop, the six Jesuits they had already killed them, we said 'we have to see if we can get out, we'll ask the Jesuits for help' so they gave us the- they helped us with the papers to get out. At fifteen days of having applied, we got the papers, and when we went back to the house, the papers came for me at like 5 in the afternoon. The papers said that we had to leave by 5 a.m. the next day. I didn't know where we were going. I knew it was to here, but I didn't know what it was like. So, it was hard because I didn't know what to do. But we left at five in the morning, we left. We didn't say goodbye to anyone... we were scared that they were going to kill us.

Roberto shared a similar story of the promptness with which he had to flee the country. Similar to Elara, his involvement in religious activities had made him a target to the military. In his town, he was watched by the commander of the civil police because of the Catholic teachings he participated in.

That year there was a command with the army, a sergeant, plus the hacienda police. Someone, an 'ear' we called them, delegated by the army in the canton to observe. The thing was that the commander called for me one day to threaten me and he told me that he called for me because he considered me a good person and he didn't want to see me disappeared as others had been disappeared. According to him, he said, "look, you've been going around with those priests dressed in white in San Miguel. Did you know those are communists?" "No, I didn't know, I just know they're priests." "Well I'm warning you if you keep hanging around them, you're going to have problems. To be Catholic, you don't have to meet up with anyone."

When he moved to San Salvador to escape poverty and surveillance, he continued to involve himself in religious activities. It had escalated to the point that one day he was kidnapped by the soldiers and left for dead on the side of the road, although he eventually found his way home. It was not until the threat extended towards his home and his family that Roberto realized he had to leave:

Until then, I had never considered leaving the country. Never. A brother of mine had recently come to suggest that I should leave for the United States. That he was going to help me with the money. I never wanted to go to the United States. I told him no. It never occurred to me that I could leave, and I never wanted to leave. But with that 
threat, it was serious...One night, my wife and I thought about the seriousness of the threat. They had already started killing people around us. We decided that I had to leave. We decided at night, and I had to leave the next morning.

It was unclear why this threat seemed to impact Roberto in a way the other ones had not before.

The promptness of his decision suggests a culmination of all the difficulties he had faced.

Additionally, the threat of endangering his family seemed to factor in; while previously he had been explicitly targeted, he had received information from a neighbour that the soldiers had begun visiting his home and asking about the particulars of his schedule.

I was friends with him, and one day he said to me, "look I want to tell you something in confidence. There is a plan being made for an attack in this area of Soyapango and yesterday someone came through asking about you, what time you get home, what time you leave and the details. I'm letting you know so that you're careful."

It was likely the invasion of the home as a sudden mixing of public danger and private space that indicated the severity of this threat as different.

\section{Arriving in Canada}

At one point or another, throughout all the interviews, participants shared their lack of desire to move to Canada. As identified in the section above, all participants were forced to leave because of a risk in their lives. As such, their experience of departure heavily impacted their perception of arriving at their country of reception.

Roberto recounted his arrival at the airport as one of the hardest of the first experiences in Canada. After having escape El Salvador for Costa Rica and then finally being granted refugee status in Canada, the experience at the airport proved overwhelming for him:

The experience in the airport - Canadian immigration was there and started to interrogate us. And I- in English and I didn't understand anything in English and the 
man wouldn't stop talking and talking, and I told him I don't understand English, I don't speak English. I was responsible for the group, my wife and my four kids. I almost cried out of frustration because I didn't speak anything.

Roberto described the complete frustration of having arrived in a new country.

Finally, it was terrible; there wasn't anyone who spoke Spanish in the airport. We had to wait until one in the morning when they went to get a woman who was...I can't remember her name. She was well known here in Toronto. She came to translate and explain the situation. At one in the morning, they finally let us through.

His experience upon entering Costa Rica had been challenging and had involved hard labour in earning money to be able to bring his family over. In recounting his experiences in Costa Rica, Roberto never shared feelings of helplessness or frustration. He often described the difficulty of his situations and the tough decisions that had to be made. It was not until arriving in Canada that he first described feelings of helplessness.

And for me, where I was responsible for answering for the family - looking for a clinic, for a school, because they were all young, it was frustrating. But I had to face it. I bought a dictionary and before entering the office to look for school, clinics and all this, I had to memorize the words for what I wanted to say. But it was terrible, very frustrating.

It also lent to feelings of inadequacy; Roberto was cognisant that as the head of the household, he was in charge of guiding his family through their experiences and recalled so in this challenging moment. He was responsible for his wife and children, yet he felt he could not give them a solution in those moments.

For Elara, when asked what she liked about Canada upon arriving, she shared:

Nothing. I didn't like anything. Because I didn't like anything because I didn't know anything, everything was new. It's a very big impact to think about what you most like. 
Elara identified that the newness of the experience was given a negative spin because the impact of having left El Salvador was severe. The process was so difficult for her family, that her husband considered leaving a year into their residency.

Yeah, he wanted to leave here. After a year he still wanted to leave.

Despite having faced physical consequences and significant risk to their lives, her husband's discontent with the new society was substantial enough to warrant consideration on his part to return to El Salvador. Elara's unhappiness with the new shocking society was also evident, as she rationalized for the benefit of her children, rather than herself.

And I told him no, that we were going to wait until the kids finished studying. And that, well yeah, we had to think first.

Similarly, Rosa described the instant culture shock she encountered when arriving in such a large city:

Oh my god, it was...I was like a little, little rabbit lost in the meadow. It was, it was a cultural shock. Much of a shock because I'm from a small town in El Salvador, so I think if we compare Toronto to El Salvador, this is the big apple. Toronto is a big city, so I remember I was lost. I was shocked.

Throughout the interview, Rosa shared that the cultural adaption was the most difficult for her. She shared that she began to feel less shock when able to establish a community of Latinx people which she met through religious organizations. 


\section{Makeshift families}

The importance of familismo was not lost on participants when they arrived in Canada. The struggles upon arriving served to highlight the necessity of a greater community like the one participants had been accustomed to back home. Isaac describes the cultural difference he perceived when comparing Canadians and Latinx individuals living in Toronto. There are an inseparable bond and connection formed when he associated with people of similar cultural background, which prompted him to create ties with these individuals. Isaac said about constructing a community in Toronto:

We used to meet new faces. We still do, when you see people with Latino face 'hey!' at least, we do. Because there is the difference between Canadians and Latinos, probably we are more approachable, more chatty.

Participants had negotiated what having a family in Canada is. Rather than closing off their families into the nuclear, many of them extended what they defined as a family beyond biological connection.

Rosa described how she, her husband and her children have gone beyond the traditional family structure in Canada:

I think you have some makeshift friends, I mean makeshift family, some friends become your family. So, we found some very good friends that we use to celebrate Thanksgiving, Christmas with. We still see them. They become your family here because our family was left behind.

\section{Language}

The language also played a significant role in the participants' ability to adjust to a new society. The inability to speak English when arriving as a new immigrant proved overwhelming for all participants and further isolated them and intensified the helplessness of their situation. 
For Roberto, shared in an example above, the struggle with language began as early as arriving at the airport. He recounted the feelings of frustration vividly and becoming emotional at the struggle which came with being spoken to in a language he did not understand.

Language permeated all aspect of participants' lives. An activity which is often taken for granted remained in Isaac's memory as he recounted the first few days during his arrival. Throughout all interviews, participants noted daily tasks which they had to participate in made harder by their incomprehension of the language. Isaac described the simple act of watching as made worse by the incomprehension of the language:

It was a very bad experience, unpleasant experience to watch TV and not understand anything.

During the preliminary questions of the interview, when asked what languages they spoke, all participants made a joke about their level of English. Participants indicated the negative memories associated with English as a second language, by answering the question regarding language with variations of "English, I think" (Isaac) or "[I] try to speak English" (Rosa).

Elara, Rosa and Isaac all commented on the necessity of English to be able to succeed in Canada. Isaac identified a situation in which his friend was unable or unwilling to learn English and the way it impacted his subsequent settlement in Canada:

Here it is a must, you learn it or go back to El Salvador. I remember a friend he was from the same town as myself. This guy couldn't probably never liked it or never did any effort to understand it, so at the end, he went back to El Salvador. So, learning it was a commitment. 
Regarding language, Isaac indicated that he believed that it is the responsibility of the individual to attain the English language. His comment on his friend never liking or never putting into an effort into learning the language do not take into account the difficulty of learning a language; instead, Isaac seemed to consider language as an essential part of the commitment to living in Canada.

Elara identified language as a reason for which she thought she was unable to achieve more in Canada. When asked about what her goals have been, Elara shared that she wanted to study to be a child psychologist but was not able to achieve this goal in Canada. She shared her frustrations with people whom she felt were equipped to strive for better, but did not do so:

I see Canadian people, people born here working as ECE and I wonder why didn't these people strive to be better? To do more? They have their own language, they know a lot of English and me, with my little English am here too... What are they doing here? Because they aren't doing something better, doctors, something better for the country and for their children. That's my question. Because I wanted to be more and I couldn't, maybe because I was old and because of my English.

Elara's comments on why people who are born speaking English do not strive for "something better" demonstrate her frustration with what she perceives as her limited capabilities and how they do not impede others.

In addition to self-perceptions of limited skills, language also impacts outward perceptions of abilities. Rosa shared her feelings on being discriminated against based on her level of English and her accent:

One of the counsellors at [service] - told me that if I wanted a job in an office, I had to change my accent. And it was hard because I could tell she was an immigrant too, her accent wasn't as hard as mine, but I felt, yeah I felt the discrimination. 
Situations like this caused Rosa to internalize outward perceptions of language capabilities.

\section{Concepts of Canada}

Overall, participants saw Canada as a land of safety and opportunities. There appeared to be a paradoxical interpretation of Canada; while many initially disliked Canada and felt there were many difficulties and hardships, all participants were grateful to the country and perceived it as fair, welcoming and a country full of potential.

Elara had described various instances in which she had wanted to do more, but was unable to either because of existing economic or language barriers:

Not a small career like this. Being an ECE is small, and I wanted to do more, I wanted to be a child psychologist, but when I looked into it at York University, I saw that each semester was very expensive...So I'd rather stay as an ECE. Because I wanted to be more, and I couldn't.

When asked about her overall experience, however, she had only positive comments to share about the outcome of her life. Despite sharing that she did not initially like Canada, Elara said about her life now:

I'm happy to be here. We're all, I mean, I achieved what I wanted. The study, the house, the car. The job. I am happy. I'm happy with what I have now. Soon I'm going to retire, and I'm seeing about that because everything was achieved.

All participants were able to move forward towards the goals they had established after arriving. There occurred a shift in the decision-making process of each person with where they wanted their lives to be. Neither of the two who had been in university continued the career path 
they had begun while still in El Salvador. Their uprooting deeply impacted the trajectory of their lives. Each individual adopted new goals under their lives in Canada.

Rosa summarized her goal orientation transformation:

I came to Canada with; I guess not much goals, I just wanted to get out of El Salvador and be able to live in a safe society, safe country. But slowly thing started to fall into place...I have immersed myself into the Canadian way. I feel lucky and fortunate that, you know I am, in this date and age, in this place in society. I think at my age it's a good place to be.

None of the participants openly identified any discrimination or barriers significant to their race. However, all did identify that significant work had to be put in to be able to adapt to Canadian culture. Three participants felt it was the personal responsibility of the individual to be able to succeed in Canada.

Isaac said about the existence of barriers in Canada:

What will have been the main barriers here in Canada? I haven't seen them...we can achieve anything we want. Sometimes I- we don't because I always say probably, I have been lazy. But we ourselves put barriers in front of us.

Isaac had throughout the interview noted the systemic and economic barriers which had and continue to plague El Salvador during the period of unrest and currently.

That was based on a few things but the guys of those lands the owners were, wanted the whole country. The people were - the poverty was very obvious, so I wish if the people in the government were more, they would have been more, like, giving away a little bit of their own then there wouldn't have been any war.

When discussing Canada, however, he tended to place the onus of responsibility on the individual. He felt that any barriers were self-inflicted: 
Here there is a lot of things to do to get a few bucks and not being, asking for it to anybody. So, people should be more productive.

Even participants that did identify barriers felt that perseverance was enough to remedy difficult situations. On being asked her final thoughts and perceptions of Canada, Rosa summarised her understanding of life in Canada eloquently:

I think that Canada is a land of opportunities, it's a land of challenges and as an immigrant, we face many hurdles, many barriers, but if you are determined and if you don't give up, you're going to reach your goals. I feel that Canada has given my family a good opportunity to live in peace.

\section{Pendientes (Transnationalism)}

Participants described their transnational ties, although they did not label their experiences as such. Instead, all participants explained the various ways in which they remained attached to their country of origin or pendientes as Roberto described it:

We're always going over there to see them and cognisant of the situation over there, for the vote. Pendientes in all manner, in prayers, in whatever can be done, the fight against mining. We're aware of everything. It's difficult to forget where you're born.

Three of the four participants recalled current knowledge of social and economic conditions of El Salvador as a whole. For Isaac, this meant remaining aware of the political strife which continued to plague not just El Salvador, but several Central American countries. Isaac explained:

The whole central America has never been a peaceful area to live. Now we here in Mexico, Honduras, Guatemala, El Salvador we still have a lot of issues, I am still afraid of going as I mentioned I was back a few months ago, but I was afraid. Now it's not a political war but its gangs and worse than before... In El Salvador, I still see problems. 
Roberto echoed a similar sentiment. Maintaining knowledge of what was taking place in other regions fortified his identity. He shared the belief that his connection with his country of origin was solidified by ongoing knowledge of the circumstances of not just El Salvador, but all of Latin America:

As someone said until the last breath, I want to give love for my patria. And not just El Salvador, but the patria of Latin America. It's important to me what happens in Venezuela, Nicaragua what the people suffer, in Honduras, in all the countries where there is so much difficulty.

While general concerns about the country as a whole were raised, the most prominent ongoing connections remained with the family. Although geographically separated, the participants' dedication to their family remained. All of the participants shared that they remained in contact with their families frequently. Rosa shared:

I call my father almost every week. Right now I'm trying to call him every day, but let's say every week I try to call him. Help him, support him economically because he's eighty-five and he needs my support. I visit him, as well.

For Roberto, the need to return to El Salvador was immediate. Shortly after arriving in Canada, he and his entire family returned for a visit and maintained the visits:

The first thing we did when we were on our feet was to travel to El Salvador to see the family. It was hard because having passed so much time outside... But we've never stopped going we go every year, at the most every two.

For three participants, remaining attached to the culture was a way of maintaining transnational bonds. This included the passing on of cultural significance to the next generations. 
For Rosa, when asked if she felt her children had connected to their Salvadoran roots, she shared they had. She did note that there was a difference in level between her and her children:

They are connected when they go there, they enjoy. They know the language. Not as well as I, but they do try. Yeah, they are connected but, not to the same degree that I am.

For Roberto, the importance of retaining culture included sharing the story of Salvadoran migration to Canada. This was not just with his own immediate family, but with everyone of a Salvadoran background living in Canada:

One wishes to continue motivating the salvadoreños and salvadoreñas to not forget our roots. Even though you were born here, outside, like my grandkids, I tell them that I want them to know why we grandparents came here, that we didn't come here as tourists. That they know there was a time of war and suffering, that there were so many thousands of people who died, who disappeared. Children who disappeared. So many invalids now because of matters of war. I don't want that to be forgotten.

\section{Analysis}

A significant portion of the available literature surrounding Central American refugees focuses on consequences individuals face when they have had to flee their country of origin because of war, violence and repression (Ginieniewicz and McKenzie, 2014). Throughout the interviews, trauma significantly featured in all aspects of the participants' experience with migration. Caruth (1991) defines trauma as the delayed and repetitive occurrence of intrusive phenomena following the experience of rapid catastrophic and upending events. While participants did not themselves identify their experiences, they did share that they had not migrated by choice. Instead, all participants indicated that they left due to violent circumstances and significant risk to their lives. As Riaño-Alcalá (2008) indicates, leaving one's country 
suddenly profoundly impacts the sensory experiences of immigrants as they attempt to make sense of their pasts, while the fear of fleeing persists. In three of the interviews, participants had to leave their homes suddenly, leaving behind their properties, belongings and extended families.

Due to the circumstances of departure, Ginieniewicz and McKenzie (2014) found that Latin American immigrants are among the three groups with the highest levels of stress. Central American refugees, in particular, are negatively impacted by stress, which is associated with depression and displacement (Ginieniewicz and McKenzie, 2014). Forced migration and displacement grant refugees a limited choice in a life-altering process. This was especially true for two participants who described situations in which their decision to leave had to be made from one night to the next morning. This restriction of an incredibly emotional, cultural and geographical shift becomes traumatic for refugees and subsequently negatively impacts levels of stress and adaption to their new country of settlement (Riaño-Alcalá, 2008).

Participants indicated their initial arrivals were made difficult by inability to navigate daily activities, further straining the mental health of participants. One participant shared that he commonly felt frustrated when he was unable to access basic needs. He emphasized that accessing basic needs was further crucial as he was responsible not only for himself but also for his family. Three participants shared that the responsibility of bringing up children in a society they did not understand and could not easily navigate was a further source of stress and uncertainty. This is concurrent with what Anison and Merali (2018) found in their study with Latinx parents who reported feeling that their parenting responsibilities were often overwhelming after migrating. This toll was characterized by various effects on the parents' mental health, including stress, fear, worry and loneliness (Anison and Merali, 2018). Latinx parents rely heavily on extended family members to aid in the socialization, culturization and 
identification process involved with raising children (Anison and Merali, 2018). Similarly, participants reported uncertainty in their decision-making processes in raising children in a different cultural context than the one they had known and the awareness of how their abilities would impact their children.

The findings reflect what the literature says regarding the way the context of departure impacts the understanding Salvadorans have regarding social and human rights issues (Ginieniewicz, 2007). Most of the participants were not directly associated with a particular political party at the time of the conflict and did not share strong political inclinations. However, all participants fled due to the exposure to political violence and developed opinions on societal issues. All four participants regarded social support as a critical tenet for social harmony and the need for community support in some capacity. This included being involved in organizational components of the Salvadoran community in Toronto or by being cognisant of personal social networks and the needs of those immediately around them.

Three participants remained aware of the social and economic conditions of El Salvador, demonstrating ongoing ties to the countries of origin. This included an awareness of the current political and social conditions of El Salvador. One participant specifically compared the economic circumstances of Canada versus El Salvador, noting that the global disparity between the two countries was a significant cause of concern. Another participant implied that they believed El Salvador would benefit from a societal structure similar to Canada's. This suggests that participants were aware of the structures they felt had benefited their lives and desired the same structures to exist transnationally. For another participant, transnationality went beyond El Salvador, sharing the belief that he felt connected to all countries in Latin America. As Carranza (2015) identifies, individual traumas are mobilized in a collective discourse. 
Leaving behind family was mentioned by all participants throughout the interviews. When these instances were brought up, participants did not mention living in fear for the family left behind but instead discussed the loss of close family ties. This is reminiscent of the literature, which has found that Latinx cultural values are characterized as family-oriented and collectivistic (Armony, 2014; Anison and Merali, 2018; Carranza, 2015). Three of the four participants identified leaving behind their extended families as the most challenging aspect of leaving because of the emotional bond which tied them together. Extended family networks often provide emotional support, which includes providing warmth, nurture, empathy, concern and love, as well as direct assistance for one's needs and responsibilities both emotionally and otherwise (Anison and Merali, 2018). One participant noted that the devotion to her father significantly complicated her decision to leave. This suggests a strong emotional bond between extended family members as well as nuclear, which has been reflected in the literature regarding Latinx family structures.

These strong ties continued to exist for all refugees almost thirty years later. All maintained continued communication with family still living in El Salvador. Transnational practices and existing technologies enable immigrants to retain connections with two or more locations by way of frequent travel and long-distance phone calls and use of cheap technology such as Skype (Carranza, 2015; Parada, 2012). All four participants shared that they did maintain frequent contact with family in El Salvador via both phone calls and attempted to visit frequently, which they defined as once a year. Carranza (2015) found that Central American immigrants, in particular, often establish transnational families as they come from regions with a strong sense of community. All four participants implied that while not economically as comfortable as they would hope for, travelling back to El Salvador remained a significant 
financial priority. They attempted to travel back to El Salvador at least once a year with the primary objective of visiting family. One participant shared that as soon as he and his family were economically able, they returned to El Salvador for a visit. Another participant echoed this same attachment, sharing that his initial return was immediate once the civil war had officially ended in order to visit the mother and siblings he had left behind.

All participants interviewed identified having existing children at the time of their forced migration. The responsibility of the family significantly impacted matters for participants who felt primarily responsible for ensuring their children were safe. Three participants indicated that their decision to leave was in part to ensure the safety for their children and the potential for a better life. Three of the participants shared that the success and stability of their children in Canada was the most crucial goal in their lives.

Most notably, language featured prominently in the narratives of all the participants. Only one participant identified overt experiences of accent discrimination during the interviews. The participant described various instances in which negative attention was drawn to her accent and the implication that she could not achieve certain levels of success professionally if she had an accent. The findings reflect what the literature says regarding accents and language as a marker of race. This is especially prominent for immigrants who arrive from colonized countries and suffer a particular process of racialization based on the accent (Cervantes-Rodriguez and Lutz, 2003). The fact that participants did not seem cognizant of this implied that they were not aware of this racialization process.

Despite not being openly aware of the racialization process, participants did perceive that there exists a level of adequate English skills, of which most seemed to think they did not possess. Two of the participants conducted the interviews in English; however, all participants 
answered the question regarding languages spoken with joking comments about the level of their capabilities. As Ostrower (2015) states, individuals spare themselves from distressing and painful effects that situations cause by using humour to cancel the possibility of negative emotions. Participants demonstrated their continued uncertainty in their capabilities and further, the negative emotions associated with speaking English. This reflected the self-perceived inadequacy of their hold on the English language and insecurity over claiming English as a language of which they had totally dominated. One participant shared that she found herself frustrated with native-born English speakers who did not strive for higher educational attainment. This signalled the understanding that having English as a primary language could open opportunities that were not available to her, as English was not her first language.

Besides this perceived language insecurity, participants also shared the idea that mastering the English language was essential to a successful life in Canada and placed a substantial value on the possibilities English could open up. This reflects what CervantesRodriguez and Lutz (2003) found regarding the hegemony of English as a requirement for practical purposes. Participants reinforced this belief throughout the interview. One participant repeatedly reiterated that English was a must and suggested that those unwilling to learn could not succeed. Participants felt it was the responsibility of the individual to adapt to the language and a reasonable expectation. Based on the responses, participants seemed to believe that they had not acquired sufficient language skills to ensure they reap all the benefits of individuals born with English as their native tongue.

Participants shared that their settlement in Toronto forced a reconfiguration of the life they had anticipated for themselves before fleeing their country. Three participants shared that they did not work in the anticipated fields they strived for while living in El Salvador. The 
findings reflect what the literature says about the reconfiguration of refugees' expectations for the future (Riaño-Alcalá, 2008). This included embracing their new realities by formulating new goals to re-orient themselves in a new society. Two of the participants admitted that they wished to have continued their studies beyond what they were able to achieve; however, when asked if they had reached their goals which living in Canada, both said they had. Both participants demonstrate the existence of two realities the one of the present and existing reality and the one of the "life left behind" of which they are still cognisant but have pushed aside in order to cope (Riaño-Alcalá, 2008).

In particular, the interviews demonstrated the involved relationship participants established with their country of settlement. Participants were grateful to Canada for accepting them and considered it a nation of opportunities. However, all participants admitted that living in Canada was not their first choice and that, had they been granted another option, they would have elected to stay in El Salvador. This paradox heavily influenced the positionality of the participants; none expressed a current interest in returning to their country of origin. However, none seemed to embrace a complete Canadianization fully. Participants did so in various ways discussed above: transnational ties, the search for a Latinx community in the GTA, and the retention of language. This reflects what Parada (2012) identifies in his own experience as a Salvadoran refugee; that he is a transnational body does not belong to one space and as a result, is a combination of multiple realities.

This creates a seemingly paradoxical reality for refugees who fled El Salvador against their wishes, who actively continue to identify with their country of origin, but who have no intentions of returning. Their perceptions of Canada are also affected by this, all appreciate and admire the country, but identify cultural differences they do not accept as their own. Riaño- 
Alcalá (2008) found that displaced Colombians in Vancouver shared a similar experience; the image of the host country is seen as one of protection and opportunity, yet the experience of the refugee is marred by distrust of a culture outside of their own. Additionally, the legacy of past experiences erodes the refugee's sense of trust. One participant demonstrated this when discussing the ease with which Canada's economic and social system could erode to reflect the corrupted system he had fled from in El Salvador.

\section{Conclusion}

\section{Future Research}

There is limited research that focuses on the Salvadoran community in Toronto. As previously noted, Salvadorans are often grouped in with the Latinx community as a whole. However, given that Salvadorans comprise the third-largest Latinx population and the largest Latin American refugee group to arrive in Canada, there does exist some literature focused on this population. Most literature found focused on policy and integration. This paper has contributed to the literature about the lived experiences of Salvadoran refugees who settled in Toronto. The personal narratives of the participants demonstrate the impact that the context of departure had on their experiences. At different points in their migration trajectory and for different reasons, each participant was impacted by the climate under which they left El Salvador.

Each participant has dealt with the experiences of trauma in a variety of ways. Further research can be conducted to delve into the impact these experiences had in shaping the way participants currently understand themselves and how it has impacted their relationships with those around them, particularly of their children. Larger sample size would allow for more 
experiences to be shared, and further exploration of the complex identity negotiations

participants undergo when forced to migrate. Further research could also look at the impact racialization had on how participants navigated their country of settlement. Moving forward, this may be best achieved in a series of interviews, rather than a single interview.

Examinations of the change in family dynamics could be further explored. There was a minimal discussion of participants' perception of how their narratives impacted those of their children. Future research could focus specifically on the dynamics between parent-children relationships.

\section{Final Thoughts}

One common theme found in the literature which did not arise in the interviews was the feeling of placelessness attributed to lack of a Salvadoran geographical community. Themes of spatial dispersal did not appear to be an issue for participants, whom all felt that they were able to establish a sense of community despite no existing geographical community. Another theme found in the literature, which was not reflected in the interviews was the racialization of colonized bodies. Apart from language, participants did not share instances in which they identified being racialized.

Despite having permitted myself moments of self-exploration during the writing of this paper, I realize that ultimately, this research was not about me. The purpose of this study was to explore the narratives of Salvadoran refugees who arrived in Canada. The narratives of those forced to flee are often lost behind the label: refugees. The word conjures a particular image, of defenselessness, of dependency and trauma. Despite the difficult migration and circumstances 
participants experienced in Canada, their stories are ones of resilience. The participants demonstrated that the experiences of refugees are more complex than they are perceived.

This major research paper is important and relevant because, during the writing of this paper, Central America continued to suffer economically, socially and politically. The territory's struggles endure, and unlike the 1980s, the Canadian government had yet to take any decisive action as it did almost thirty years ago. The importance of this research was expressed beautifully by one of the research participants, Roberto. The interview was conducted in Spanish, and it is vital to share his words as they were spoken.

Porque tengo el tema, la tesis que aprendí de un profesor, yo estaba muy joven, que decía, "Las palabras se las lleva el viento, hay que escribir las para que se queden. Entonces yo lo mismo digo, toda esta experiencia, aunque sea resumida, hay que contarla, que quede escrita, para que conozca nuestra futura generación. Y no solo para conocerla, pero para que podamos mantener la solidaridad con el pueblo. Que todo el tiempo va a haber necesidad; la pobreza, la defensa de los derechos humanos, nunca termina.

Because I have the idea, a thesis that I learned from a teacher when I was very young, he would say "The words are carried by the wind; they must be written down so that they remain." So I think the same, that this entire experience, even though it's only a summary, has to be told has to be written so that it is known by future generations. And not just to know of it, but so that we may maintain solidarity with the pueblo. There will always be needs; poverty - the protection of human rights never ends.

In 1982, an article in The Globe and Mail article announced: "Canadian government representatives have started interviewing Salvadorean refugees facing deportation from U.S. detention centres and admitting them to Canada." Though the article was written over thirty-five years ago, it reads as if it applied during the writing of this paper. The reaction of the Canadian government has not been the same. 
The exploration of the past enables us to consider the future. Three of the participants acknowledged that the needs of the people of Central America remain pressing. It is pertinent to consider the narratives of the individuals who shared; their difficulties, their struggles, their gains, their losses, the good and the bad when stopping to think of our present. 


\title{
Appendix A
}

\section{Ryerson \\ tomatos \\ Participants Needed for Research Study on Salvadoran Refugees}

\author{
Are You: \\ From El Salvador? \\ Did you come to Canada under either the refugee stream of private sponsorship or \\ government sponsorship? \\ Did you arrive between 1980 to $1992 ?$ \\ Did you settle in Toronto upon your arrival?
}

If you answered yes to the above questions you are invited to volunteer for the study of the Settlement Experience of Salvadoran Refugees in Toronto. We are seeking 4 to 6 participants. You are not eligible for this study if you were a sponsored family member or a child who migrated with your parent(s)

You will participate in an interview where you will discuss your experience of moving to Canada, building your life in Toronto and your current experience living here.

Your participation will involve an interview of approximately an hour and a half

In appreciation of your time, you will receive transit tokens.

If you are interested in participating in this study or for more information, please contact: veronica.escobar@ryerson.ca

This research is being conducted by Veronica Escobar Olivo as part of a Masters degree 


\section{Appendix B}

Ryerson University

Dear [organization],

My name is Veronica Escobar Olivo, I am a Masters student at Ryerson University and I am recruiting participants for a research study exploring the experiences of Salvadoran refugees who migrated between 1980 and 1992 and settled upon arrival in Toronto. I am hoping to connect with Salvadoran refugees who are willing to talk about their experiences in Toronto upon settling in an interview lasting approximately 90 minutes.

I am looking for participants who are of Salvadoran background, who migrated to Canada between 1980 and 1992 and who settled in Toronto. Those who came as sponsored family members or children with their parents are not eligible to participate.

Participants will be reimbursed for travel expenses in the form of two TTC tokens.

Paticipation is voluntary and confidential. The goal of this study is to better understand the experience of Salvadoran refugees who came to Canada and to give participants a chance to share their experiences. I am including a copy of the recruitment poster with more information that you can hopefully distribute at your organization.

If you have any questions or concerns, please contact the researcher, Veronica Escobar Olivo at veronica.escobar@ryerson.ca.

This study has been reviewed by the Ryerson Ethics Board (protocol number REB 2019-221).

Thank you for your time. 


\section{Appendix C}

\section{Ryerson}

University

Dear [name],

My name is Veronica Escobar and I am a Masters candidate at Ryerson University. You are being invited to participate in a research study. The focus of the research is to explore how Salvadoran refugees who came to Canada between 1980 and 1992 describe their settlement process.

To participate you need to be first generation refugee from El Salvador who arrived in Canada between the years of 1980 and 1992 and who settled in Toronto. Individuals who came as children or sponsored family members are not eligible for this study. If you agree to volunteer you will be asked to participate in a one-on-one interview where you will share the reason for your departure, your experience of migration and your settlement experience in Toronto. Your participation will involve an interview that will last up to 90 minutes.

Your participation is completely voluntary and if you choose not to participate it will not impact our relationship or your relationship with Ryerson University. You will be reimbursed for travel expenses in the form of two TTC tokens.

If you are interested in more information about the study or would like to volunteer, please email me at veronica.escobar@ ryerson.ca.

The research project has been reviewed by the Ryerson Ethics Board (REB protocol number REB 2019-221). 


\section{Appendix D}

\section{General Questions}

- What languages do you speak?

- In what year did you come to Canada?

- How old were you when you arrived in Canada?

- Marital status?

- Kids? If yes, how many?

\section{Departure}

- Can you describe your life in El Salvador?

○ In the events leading up to your migration?

- Why did you migrate to Canada? (Specifically this country)

\section{Arrival}

- Did you come as a private sponsored refugee, government sponsored refugee or other?

○ Can you please talk about your experiences through this process of sponsorship?

- Can you tell me a little about what your experience was during the first three years of your arrival?

What was the hardest part?

- What do you wish had been different?

○ What did you enjoy/appreciate?

- Did you have family here in Toronto prior to moving? Who?

○ In Canada?

- Have they supported you? In what way?

\section{Settlement}

- Where do you find a sense of community?

○ How did you connect with this community?

- Have you worked and/or studied in Canada?

- In what area?

-What does your work mean to you? 
- What have been your goals while living in Canada?

- Have there been any barriers that have kept your from achieving them?

○ What could have helped you?

- How do you describe your overall experience of living in Canada?

\section{Today}

- What are your relationships like with your family (IF have kids: with your kids? With your partner?)

- Do you maintain contact with El Salvador? (Visiting, speaking to family members, friends etc.)

- Is there anything about your experience that you'd like to share before we end the interview? 


\section{References}

Amnesty International. (1980). Amnesty international report 1980. Retrieved from Amnesty International website: https://www.amnesty.org/en/

Andrews, M., Squire, C., \& Tamboukou, M. (2013). Doing narrative research (Second ed.) SAGE.

Anison, M. and Merali, N. (2018). Latino immigrant parents' experiences raising young children in the absence of extended family network in Canada: Implications for counselling. Counselling Psychology Quarterly, 31(4), 408-427.

Armony, V. (2014). Latin American communities in Canada: Trends in diversity and integration. Canadian Ethnic Studies, 46(3), 7-34. doi:10.1353/ces.2014.0043

Baksh, B.S. (2016). Clarity and confusion: Epistemological struggles with Islamic identity and secular education. Qualitative Social Work, 15(5-6), 640-649.

Bamberg, M. (2012). Narrative practice and identity navigation. In Holstein, J. A., \& Gubrium, J. F. Varieties of narrative analysis (pp. 99-124). Thousand Oaks, CA: SAGE Publications, Inc. doi: $10.4135 / 9781506335117$

Benoot, C., Hannes, K., \& Bilsen, J. (2016). The use of purposeful sampling in a qualitative evidence synthesis: A worked xample on sexual adjustment to a cancer trajectory. BMC Medical Research Methodology, 16(1), 21-21. doi:10.1186/s12874-016-0114-6

Bernhard, J.K., Goldring, L. and Landolt, P. (2011). Agenda setting and immigrant politics: The case of Latin Americans in Toronto. American Behavioral Scientist, 55(9), 1235-1266.

Bungay, V., Oliffe, J., \& Atchison, C. (2016). Addressing underrepresentation in sex work research: Reflections on designing a purposeful sampling strategy. Qualitative Health Research, 26(7), 966-978. doi:10.1177/1049732315613042

Butler, J. (1993). Poststructuralism and postmarxism. Diacritics, 23(4), 3.

Carranza, M.E. (2008). Salvadorian women speak: Coping in Canada with past trauma and loss. Canadian Social Work Review, 25(1), 23-36.

Carranza, M.E. (2009). Salvadorian women's diaspora: Ana Rivera's story. Canadian Woman Studies, 27(1), 140-145.

Carranza, M.E. (2012). Salvadorian ethnic pride: A bridge for reducing mother-daughter conflict due to acculturation into Canadian society. Canadian Social Work Review, 29(1), 61-85.

Carranza, M.E. (2012). Cross-border family therapy: An innovative approach to working with Latina refugee women in therapy. Women \& Therapy, 35, 57-67. 
Carranza, M.E. (2015). Protesting against mothers' surveillance: Salvadorian mothers and their daughters negotiating adolescence in a foreign context. Journal of Family Social Work, $18,106-122$.

Carranza, M.E. (2018). International social work: Silent testimonies of the coloniality of power. International Social Work, 61(3), 341-352.

Caruth, C. (1991). Unclaimed experience: Trauma and the possibility of history. Yale French Studies, 75, 181-192.

Ceci Misoczky, M. (2011). World visions in dispute in contemporary latin america: Development x harmonic life. Organization, 18(3), 345-363. doi:10.1177/1350508411398730

Cervantes-Rodriguez, A.M. and Lutz, A. (2003). Coloniality of power, immigration and the English-Spanish asymmetry in the United States. Nepantla: Views from the South, 4(3), 523-560.

Charles, C., Gentles, S. J., Ploeg, J., \& McKibbon, K. A. (2015). Sampling in qualitative research: Insights from an overview of the methods literature. The Qualitative Report, 20(11), 1772.

Ching, E. K. (2014). Authoritarian el salvador: Politics and the origins of the military regimes, 1880-1940 University of Notre Dame Press.

Cohen, N., \& Arieli, T. (2011). Field research in conflict environments: Methodological challenges and snowball sampling. Journal of Peace Research, 48(4), 423-435. doi:10.1177/0022343311405698

Da, W.W (2002). Salvadorians in Canada: Contexts of departure and arrival. Latin American Research Group, 1-12.

Darling, J. (2008). The 3Rs of El Salvador's civil war: Revolution, religion and radio. Journal of Media and Religion, 7, 132-149. doi: 10.1080/15348420802223072

De Fina, A., \& Georgakopoulou, A. (2015). The handbook of narrative analysis Wiley Blackwell.

De La Cruz, R. (2017). No asylum for the innocent: Gendered representations of Salvadoran refugees in the 1980s. American Behavioral Scientist, 61(10), 1103-1118.

Dezza, G. (2017, January 16). Las poderosas imágenes de la sangrienta guerra civil que terminó hace 25 años en El Salvador. BBC Mundo. Retrieved from https://www.bbc.com/mundo/noticias-america-latina-38613136

Dwyer, R. and emerald, e. (2016). Narrative research in practice: Navigating the terrain. In Dwyer, R., Davis, I., \& emerald, E. (Eds.). (2016). Narrative research in practice: Stories from the field. Retrieved from https://ebookcentral-proquestcom.ezproxy.lib.ryerson.ca 
Elliott, J. (2005). Using narrative in social research. London, England: SAGE Publications Ltd doi: $10.4135 / 9780857020246$

Elliott, J. (2005). Using narrative in social research: Qualitative and quantitative approaches SAGE.

García, M.C. (2006). Seeking refuge: Central American migration to Mexico, the United States and Canada. University of California Press.

Giddens, A. (1984). The constitution of society: Outline of the theory of structuration. Polity Press.

Ginieniewicz, J. (2007). The scope of political participation. Journal of International Migration and Integration / Revue De l'Integration Et De La Migration Internationale, 8(3), 327345. doi:10.1007/s12134-007-0025-9

Ginieniewicz, J., \& McKenzie, K. (2014). Mental health of Latin Americans in Canada: A literature review. International Journal of Social Psychiatry, 60(3), 263273. https://doi.org/10.1177/0020764013486750

Gould, J.L. \& Lauria-Santiago, A. (2004). "They call us thieves and steal our wage": Toward a reinterpretation of the Salvadoran rural mobilization, 1929-1931. Hispanic American Historical Review, 84(2), 191-237.

Hathaway, J.C. (1988). Selective concern: An overview of refugee law in Canada. McGill Law Journal, 33, 676-715.

hooks, b. (1990). Yearning: Race, gender, and cultural politics Between the Lines.

International Commission of Jurists. (1979). For the rule of law: The review. Retrieved from International Commission of Jurists website: https://www.icj.org/

Jacob, A. G. (1994). Social integration of Salvadoran refugees. Social Work, 39(3), 307-312. doi:10.1093/sw/39.3.307

Jones, M.R. and Karsten, H. (2008). Giddens's structuration theory and information systems research. MIS Quarterly, 32(1), 127-157.

Mignolo, W. D. (2007). Delinking: The rhetoric of modernity, the logic of coloniality and the grammar of de-coloniality. Cultural Studies (London, United Kingdom), 21(2-3), 449514. doi:10.1080/09502380601162647

Mishler, E. G. (1986). Research interviewing: Context and narrative Harvard University Press.

Noy, C. (2008). Sampling knowledge: The hermeneutics of snowball sampling in qualitative research. International Journal of Social Research Methodology, 11(4), 327-344. doi:10.1080/13645570701401305

Nourpanah, S. (2016). Cultural stories: Afghan refugee narratives of daily life on Canada's east coast. In Poteet, M., \& Nourpanah, S. (Eds). After the flight: The dynamics of refugee settlement and integration Cambridge Scholars Publishing. 
Ostrower, C. (2015). Humor as a defense mechanism during the holocaust. Interpretation: A Journal of Bible and Theology, 69(2), 183-195. doi:10.1177/0020964314564830

Owolabi, K. A. (2001). The quest for method in african philosophy: A defense of the Hermeneutic-Narrative approach. The Philosophical Forum, 32(2), 147-163. doi:10.1111/0031-806X.00057

Parada, H. (2012). The mestizo refuses to confess: Masculinity from the standpoint of a Latin American man in Toronto, In Moffatt, K. J. (Ed). Troubled masculinities: Reimagining urban men University of Toronto Press.

Poteet, M. and Simmons, A. (2016). Not boxed in: Acculturation and ethno-social identities of Central American male youth in Toronto. Int. Migration \& Integration, 17, 867-885.

Quijano, A. (2000). Coloniality of power and eurocentrism in Latin America. International Sociology, 15(2), 215-232.

Riaño-Alcalá, P. (2008). Journeys and landscapes of forced migration: Memorializing fear among refugees and internally displaced Colombians. Social Anthropology, 16(1), 1-18.

Ryan, P. (1988). Compassion or expediency: The overseas selection of Central American refugees. Prepared for the office of Dan Heap M.P.

Shayne, J. D. (1999). Gender revolutionary bridges: women in the Salvadoran resistance movement (1979-1992). Latin American Perspectives, 26(3), 85-102.

Simmons, A.B. (1993). Latin American migration to Canada: New linkages in the hemispheric migration and refugee flow system. International Journal, 48(2), 282-309.

Singer, J.A. (1995). Seeing one's self: locating narrative memory in a framework of personality. Journal of Personality, 63:3, 429-459.

Sky, I. (2016). Searching for my palm tree: Epistemological journeying of a child welfare doctoral student. Qualitative Social Work, 15(5-6), 619-627.

Suri, H. (2011). Purposeful sampling in qualitative research synthesis. Qualitative Research Journal, 11(2), 63-75. doi:10.3316/QRJ1102063

Tario, J. (2017). In-between cultures: Becoming latin american Canadian

Teelucksingh, C. (2006). Claiming space: Racialization in canadian cities Wilfred Laurier University Press.

Veronis, L. (2007). Strategic spatial essentialism: Latin Americans' real and imagined geographies of belonging in Toronto. Social \& Cultural Geography, 8(3), 455-474.

Woodley, X. M., \& Lockard, M. (2016). Womanism and snowball sampling: Engaging marginalized populations in holistic research. The Qualitative Report, 21(2), 321. 
Young, M. Y. (2001). Moderators of stress in Salvadoran refugees: The role of social and personal resources. The International Migration Review, 35(3), 840-869. doi:10.1111/j.1747-7379.2001.tb00043.x 